\title{
The system of main categories of integral assessment of mining technologies
}

\author{
Gennadii Sekisov $^{1 *}$ \\ ${ }^{1}$ Mining Institute of Far Easten Branch of Russian Academy of Sciences, Khabarovsk, Russia
}

\begin{abstract}
The evaluation of rationality and efficiency of mining technologies of mining operations and the development of solid commercial minerals deposits as a whole is given. It is considered and justified as big and rather topical problem. Methodological framework of its solution is represented by a system of evaluation categories the base of which is represented by criteria, indices and parameters of mining technologies. Original component of evaluation system is a some kind of sub-system of evaluation criteria. Indices for each type of criteria representing in some extent their content are represented as a central unit, the parameters of mining technologies are represented as components of evaluation system, and subsequently substantial expression of criteria, and indices. Key words: Mining technologies, mining operations, solid commercial minerals deposits, deposits development, parameters of mining technologies, evaluation categories, evaluation criteria, evaluation indices and evaluation parameters.
\end{abstract}

\section{Introduction}

Reliable and timely evaluation of the development and use of mineral resources and products has always be playing an important part, but especially great significance in our country it gains currently: first, in connection with the transfer of economics to market relations, second due to the absence so far of genuine advanced methodological frameworks of evaluation: rationality and efficiency of mining operations; development of deposits and their use as a whole. This is a major and complex issue which for it to be solved requires the accomplishment of special and extensional researches and analysis. Therefore, in this work we justify and represent one of the most essential components of original scientific and methodological frameworks of mineral deposits development - system of evaluation categories.

It is unrealistic to count on the creation in rather short terms of comprehensive methodological frameworks of this evaluation with plurality of types of mineral deposits themselves and social and economical, organizational and process, technical and other conditions of their development. Since we deal with a very branching and complex scientific and production system, on given stage this refers to only original frameworks of aggregative evaluation of efficiency of the development of one of the main and the most

\footnotetext{
*Corresponding author: adm@igd.khv.ru
} 
wide-spread types of mineral features - ore deposits and their major components. Originally, we base upon the system of evaluation categories being put forward which includes criteria, indices and parameters in hierarchical population and interrelation. As often as not in mining literature and, especially, in practice they are put on the same level being considered as synonyms of "rational" and "comprehensive" concepts. While these conceptual and terminological categories are different in sense. In respect to specific conditions, the most comprehensive justification of "comprehensive subsoil development" category was provided by academic M. I. Agoshkov [1].

We provide substantive definitions of the following ones of major conceptual and terminological categories in the field of subsoil mining and industrial development:

Development of deposits - production and economic acquirement of mineral deposits and mineral components being contained in them, concentrated within natural or residue mineral formation of industrial or sub-industrial significance.

Rational development of deposit - reasonable and feasible production and economical acquirement of industrial concentration of mineral deposit (or deposits) and mineral components being contained in them within natural, natural and residue mineral formation.

Effective development of deposit generally - resultant production and economical acquirement of industrial concentration of mineral deposit (or mineral deposits) and mineral components being contained in it (in them) within a specific natural, natural and residue formation in case of following social, ecological and legal regulations.

Optimised development of deposit - the most advantageous in integrated expression (economical, ecological, social and legal) production acquirement of industrial concentration of mineral deposit (or mineral deposits).

Comprehensive development of deposit (mineral feature) in the own sense acquirement of mineral deposits concentrated in industrial and economical quantities within specific mineral formation or mineral feature.

\section{Evaluation criteria for the development of mineral deposits and mining operations}

Generalising and analysing economical and technical literature, the author has determined essential discrepancies in interpretation and definition of concepts of "criterion" categories although some authors, specifically, academic T.S. Khachaturov defining "efficiency of social production" category, proceed from wide interpretation of "criterion" and "index" concepts [2]. Unfortunately, quite a number of economists and representatives of some other specialities identify "criterion" concept with "index" concept. Considering widely used literature, primarily reference one, various interpretations and definitions of these terms are noted. Similar approach we applied as well to establish the essence of related categories, in particular - "index" or "indices", "parameter" and "parameters", at that versus "criterion" concept [3-5].

The analysis of interpretations and definitions of categories "criterion", "index", "parameter", allows deducing that "criterion" (if broadly defined) - this is a kind of general standard of some activity. Subsequently, it is necessary to judge from the fact that criterion was understood to be the most general principle, specific feature of evaluation of some human's activity, and index was to be understood as one or another (mathematical, symbolic, verbal, etc.) expression of this activity level as a whole, its separate aspect or a row of aspects simultaneously, i.e. the expression of criterion level.

Famous classical expression may serve as satisfactory evidence of feasibility of such approach: "first try then trust". 
Hereafter, we judge by the fact that criterion is, essentially, a general specific principle of evaluation of one or another activity, specifically, deposits development.

Having made specific researches, we put forward a general system of evaluation criteria based on the assumption of their range, including evaluation criteria for the development of deposits, including the gold ore deposits, such as:

integrated, generalizing;

Quasi-integrated (nearly integrated) criteria, i.e. close by its range to integrated criterion, but other than such (completely);

Sub-integrated (sub-generalizing);

aggregative; nodal and differential (elemental).

As an original criterion of the development of deposits and mining operations, "deposit development rationality" is put forward. From the viewpoint of this criterion, the development may be generally rational and irrational.

"Efficiency" should be referred to integrated criteria, "optimality" — to quasi-integrated criteria representing various but incomplete combinations of sub-integrated criteria, for example, "social and ecological rationality of gold or deposits development".

\section{Evaluation indices of deposits development mining operations}

In general meaning $[6,7]$ and in specified interpretation, the index of some activity, including, naturally, the development of deposits and mining operation, is a certain expression by the form of a particular level of activity. In relation to a criterion, the index is a kind of means of its specific expression in one or another informative form: mathematical, symbolic, signalling, etc. Great variety of indices types, even more quantity of types, appear from the given above system of evaluation criteria. Their full disclosure is possible only within the frames of some sort of a systems, the development of which - special, wide and detailed survey. In this work, only general rank system of evaluation indices is stated.

In accordance with the above established ranking of evaluation criteria we distinguish following rows of indices:

1. Integrated indices expressing integrated development evaluation criteria;

2. Quasi-integrated indices reflecting quasi-integrated criteria;

3. Sub-integrated indices expressing sub-integrated criteria;

4. Aggregative indices expressing aggregative criteria;

5. Differential (elemental) indices expressing accordingly differential criteria.

From the perspective of categorization of evaluation itself, it is feasible to distinguish indices of three various kinds: quantitative evaluation indices, qualitative evaluation indices and combined (quantitative and qualitative) evaluation indices.

High categories evaluation criteria indices are given below.

The following may be referred to integrated indices:

1. Rationality indices.

2. Efficiency indices.

3. Optimality indices.

Similar and equivalent to the criteria system, also systems of types of quasi-integrated, sub-integrated, aggregative and differential (elemental) indices are distinguished.

Quasi-integrated indices by its gradation and description are analogues to quasiintegrated criteria. Comprehensiveness of the development of deposits and other mineral features should be referred to one of the most important quasi-integrated indices of evaluation. 
It is proposed to use rationality and efficiency indices as sub-integrated ones: economical; ecological; social; process; technical, etc. expressed by relevant factors.

Currently, quantitative evaluation of the level of rationality is rather handicapped due to the following reasons:

- first, the content itself of "rationality of development" category is not expressed quite clearly (definitely) from the perspective of its quantitative expression;

- second, even if it is granted that clear expression of its content is accomplished, at current stage it is rather encumbering to evaluate it. Since it is still impossible to bring down to a common denominator, adequately and in terms of quantity, such its major aspects as economical, ecological, social, etc. likewise so far the situation roughly is with reliable, authentically integrated quantitative evaluation of development efficiency.

In these conditions it is possible to evaluate the rationality of mineral deposits development in terms of quality. The rationality index of deposit development $(\mathrm{Po})$ is put forward as integrated index of such evaluation. Whereby, five levels of rationality of deposits development are distinguished which may be established as a result of its qualitative evaluation:

- Rather high degree of rationality (Rrh);

- High degree of rationality $(\mathrm{Rh})$;

- Mid level of rationality (Rm);

- Not high level of rationality (Rnh);

- Low level of rationality (Rl), i.e. rationality of development is on the edge of irrationality. when

It is proposed to refer such its level to rather (or exclusively) high degree of rationality

$$
R_{\text {gen }}=R_{r h}>R_{h}>R_{m} \rightarrow \max ,
$$

It is possible when the level of major components (quasi- and sub-integrated indices) are rather high ( $50 \%$ and more) and high.

It is feasible to refer to high degree of rationality its level when

$$
R_{h} \leq R_{r h} \geq R_{h}
$$

This, in turn, is possible when all its major large components have high level or predominately high one, and the rest part (lesser) — not lower than mid one.

Mid level of rationality is its level with

$$
R_{m} \leq R_{h} \leq R \leq R_{r h}
$$

This is possible under condition when all its components have mid level or generally mid level and only its small part - not high and high.

Pursuant to the above stated approach, we refer rationality to not high level when

and to its low level when

$$
R_{n h s} \leq R_{m} \leq R_{h}
$$

$$
R_{l} \leq R_{n h} \leq R_{m}, \text { as per } R_{l}>I r,
$$

where $I_{r}$ - the level of irrational deposits development

Since at present it is impossible to strictly express the level of rationality in terms of quantity, its establishment may be accomplished based upon, primarily, expert evaluation and rank correlation. Likewise, it is proposed to determine the level of quasi- and subintegrated rationality.

No less various appear indices reflecting criteria of efficiency which is to be represented by such its components as economical, ecological, legal, process, technical efficiency.

Specifically, it is proposed to use qualitative and quantitative expression of efficiency factor. At that, as its integrated characteristic, it is feasible to use an index expressed in rank scale and changing five discrete gradations:

1. Rather high efficiency or the highest efficiency $\left(\sum E r h\right)$, i.e. when 
2. High efficiency $\left(\sum E h\right)$, i.e. when

$$
\sum E_{r h} \rightarrow \max
$$

$$
\sum E_{h}<\sum \ni_{\mathrm{BB}}
$$

3. The efficiency of mid level $\left(\sum E m\right)$, i.e. when

4. Low efficiency $(E l)$, i.e. when

$$
\sum \ni c \approx \frac{Э в+Э н}{2}
$$

5. Rather low efficiency $\left(\sum E r l\right)$, i.e. when

$$
\sum E_{r l}<\sum \ni_{\mathrm{H}} \rightarrow \min
$$

Efficiency, in particular the efficiency of deposits development (EDD), may be considered as rather high if its main components (economical, social, ecological, etc.) are rather high or the majority of components refer to rather high level and the rest to high level.

Other levels of $E_{D D}$ are established as follows:

- high level of its components if of the same high level or from the combination of components of rather high, high and mid levels;

- mid - from components of mid level or from the combination of high, mid and, possibly, one component of low level;

- rather low - from components of rather low or predominately low level.

In case of different, including in case of significant discrepancies in levels of separate components, the level of full $E_{D D}$ is established based upon average weighted evaluations approach. It is suggested that, in turn, level of each component of $E_{D D}$ may be established by one of known mathematical and statistical method, including rank correlation method or via expert evaluation.

In order for preliminary or approximate quantitative evaluation of $E_{D D}$ effectiveness, quasi-integrated index is brought in, conventionally called as a index of net effectiveness $\left(E_{D D}\right)$ expressed by the dependence of general view:

$$
\ni_{\text {ом }}=\sum_{j=1}^{n} R_{j}-\sum_{j=1}^{m} S_{j}-\sum_{k=1}^{i} D_{k}
$$

where $P_{j}$ - reduced (both by time factor and by effect) positive result obtained from the production and the use of $j$-products with effective deposit development (in monetary or natural expression);

$S_{j}$ - reduced value of $j$-type of expenditures for obtainment of positive results and prevention of negative consequences related to complete cycle of effective development of deposit;

$D_{k}$ - reduced value of $k$-damage caused by negative consequences of deposits development or mining operations;

$n$ - quantity of positive results obtained from effective deposit development or mining operations;

$m$ - quantity of types of expenditures carried ut in case of effective deposit development or mining operations;

$i$ - quantity of types of damage (negative consequences) associated with deposits development or mining operations.

Integrated indices of efficiency of deposits development $\left(E_{D}\right)$ and mining operations may be expressed by the following dependence of general view:

$$
\ni_{\mathrm{o}}=\sum_{1}^{t} P_{\Pi}+\sum_{1}^{m} P_{n m}+\sum_{1}^{n} P \rightarrow \max
$$


where $P_{n}-$ level of efficiency of the development of natural mineral resources and mining operations within deposit and used raw materials over a period $t_{i}$ years;

$P_{n m}-$ level of efficiency of the development of natural and residue features and use of obtained mineral raw materials over the period $t_{i}$ years;

$P_{m}$ - level of efficiency of the development of residue features and use of their mineral raw materials over the period $t_{i}$ years;

$m$ - quantity of natural and residue mineral features formed during the development of original natural deposit or by mining operations;

$n$ - quantity of residue features formed in the process of the development of original natural deposit and formed at that natural and residue features, and also in case of using their mineral raw materials.

Table 1. General categories of parameter of the system of mining operations and technologies of ore deposits development

\begin{tabular}{|c|c|c|}
\hline \multicolumn{2}{|r|}{ Attributes } & \multirow[t]{2}{*}{ Categories of parameters and their types } \\
\hline Item & Description & \\
\hline 1 & $\begin{array}{l}\text { Parametrical } \\
\text { purpose }\end{array}$ & $\begin{array}{l}\text { Mining technologies: geological exploration, mineral features } \\
\text { development, deposits mining, mining and development } \\
\text { (mainly overburden mining), mining operations, mineral } \\
\text { secondary development, processes }\end{array}$ \\
\hline 2 & Level of parameters & $\begin{array}{l}\text { Integrated, sub-integrated, aggregative, sub-aggregative, } \\
\text { nodal, link, elemental }\end{array}$ \\
\hline 3 & $\begin{array}{l}\text { Performance } \\
\text { (efficiency and } \\
\text { expenditures) }\end{array}$ & $\begin{array}{l}\text { General efficiency, economical, ecological, power, social, } \\
\text { process, technical, geomechanical, etc. }\end{array}$ \\
\hline 4 & $\begin{array}{l}\text { Production } \\
\text { space }\end{array}$ & $\begin{array}{l}\text { Territoriality: process, geometrical, geomechanical, } \\
\text { geological, geophisical, physical and geographical, etc. }\end{array}$ \\
\hline 5 & $\begin{array}{l}\text { Production } \\
\text { time }\end{array}$ & $\begin{array}{l}\text { Duration: process preparation. Operational stage, process } \\
\text { impact on production process entities and as a whole mining } \\
\text { technologies, mineral products production }\end{array}$ \\
\hline 6 & Quantity & $\begin{array}{l}\text { Process quality: physical, mathematical (including } \\
\text { geometrical), labour-intensive, consumptive, consumable, } \\
\text { range, etc. }\end{array}$ \\
\hline 7 & Quality & $\begin{array}{l}\text { Process quality: innovativeness, selectiveness, reliability, } \\
\text { productivity, small waste, resource-saving, economical, } \\
\text { ecological, power, social, adaptability, versatility. }\end{array}$ \\
\hline 8 & Demand & Needs, demand, consumption, realization \\
\hline 9 & $\begin{array}{l}\text { Application } \\
\text { conditions }\end{array}$ & $\begin{array}{l}\text { Process and working conditions: Physical and geographical, } \\
\text { common geological, mining and process, ecological, } \\
\text { economical, power, infrastructure, technical, legal. }\end{array}$ \\
\hline 10 & $\begin{array}{l}\text { Informativeness and } \\
\text { information }\end{array}$ & $\begin{array}{l}\text { Process informativeness: its integrity, operational efficiency, } \\
\text { authenticity, reliability, completeness, usefulness, valuation. }\end{array}$ \\
\hline 11 & Movement & $\begin{array}{l}\text { Movement: intensity, consistency, mobility, variability, } \\
\text { stability, safety, etc. }\end{array}$ \\
\hline 12 & $\begin{array}{l}\text { Infrastructure } \\
\text { common-process }\end{array}$ & $\begin{array}{l}\text { General mining mining and process infrastructure: transport, } \\
\text { power, communication, information, construction, etc. }\end{array}$ \\
\hline
\end{tabular}




\section{System sub-complex of mining technologies parameters}

As a rule, values characterizing main properties of certain features - systems, process, events - are referred to parameters $[8,9]$.

In respect to problem set-up by us, parameters are values reflecting main properties of one or another mining technology, its components. Quantitative definition of parameters, i.e. values of given technical system and its main components is provided for being accomplished on the following stages of scientific research since it is rather volumetric subproblem. On this stage, volumetric definition of the system of mining technologies parameters themselves is accomplished in respect to peculiarities of the development of gold ore deposits of Russian Far East. In relation to methods of the development of gold ore deposits and to methods of the development of ore deposits as a whole, a specific, specifically - hierarchical system of given parameters is being formed by us from the perspective of their volumetric expression. At that, keeping to the system of main attributes given in the table 1. Within which general categories and types of parameters are reflected.

Criteria, indices and parameters are considered and justified as the most essential components of general evaluation system. All these taken all together are feasible to be referred to theoretical justification methodological frameworks of parameter system complex volumetric evaluation. Process is a basic system as main feature of parameter system complex being represented by us. In the capacity of peculiar parameters of ore deposits as one of main features of mining technologies from the perspective of substantivity of features given in fig. 1 .

Parameters of substantial features - geological and production parameters of deposit quantitative characteristics of mineral deposits banks and their natural properties, to a significant extent predetermine not only conditions but also performance of deposit mining, extraction and mineral raw materials processing and half-finished products.

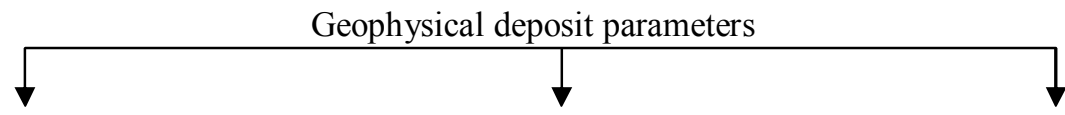

Seismic activity

Physical and technical parameters

Hydrophysical parameters

parameters

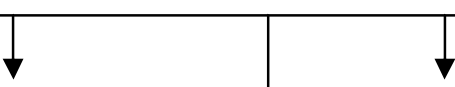

Gravitational

$\downarrow$

Electrophysical
Magnetical and physical

Fig. 1. Main geophysical parameters of ore deposits and built-up rock formations

Geochemical parameters of solid minerals deposits and, primarily, - gold ore ones - is, mainly, the quantity of types of commercial and harmful components of deposits, and as a whole and its components; their quantity and combination of components; the content of components in commercial mineral(s); chemical composition of rock formations building up geological bodies of deposits.

The following are referred to main categories of geophysical parameters of deposit as development target: physical and technical properties of rock formations and masses, seismic activity of mining and geological features, Hydrophysical properties and some other. 


\section{Results}

It is feasible to refer the following to main results of the above-stated:

1. Parametrical categories of mining technologies evaluation as well as hierarchical system of mining technologies comprehensive evaluation consisting of criteria, indices and parameters are represented systematically.

2. Sub-system of evaluation criteria is determined and represented by original component block of this system.

3. Sub-system of indices and their composition, criteria level, the dependence of original types are determined for their quantitative expression.

4. Sub-systems of indices of mining technologies quantitative evaluation, and in a certain degree and mining operations are established. At that, they are represented in hierarchic sequence.

5. Original definitions of main concepts — "criterion", "index", and "parameter" as well as basic categories, such as rationality, effectiveness, optimality and comprehensiveness are corrected and reflected in accordance with modern conditions of mining operations.

\section{Conclusions}

1. For the first time, hierarchical system of evaluation categories is proposed in complex relationship of components.

2. It is possible and feasible to reliably accomplish the use of substantively established categories of the evaluation of mining technologies and mining operations in the shape of hierarchical system of criteria, indices and parameters as scientific and methodological means of justification of rational modernization of traditional, and most significantly creation and effective practical use of innovative mining technologies.

\section{References}

1. Mikhail Agoshkov. Publishing house of Academy of Sciences of the USSR Research Institute of Comprehensive Exploitation of Mineral Resources. (1986).

2. Tigran Khachaturov. Academy of Sciences of the USSR, Economics division, $2^{\text {nd }}$ edition. Nedra, (1987).

3. Gennadii Sekisov, Nikolai Zykov. The development of mineral features and evaluation method. - M.: "Mining book" Publishing house. pp 383-391. (2012).

4. Statistical criteria. Great Russian Encyclopedia, page 65.

5. Criteria of oil and gas geological exploration efficiency. Geological dictionary. "Nedra" Publishing house. 2. p 375. (1978).

6. Economic parameters! Great Russian Encyclopedia. "Sovetskaia Entsiklopedia" research publishing house. 26. p 598. (2014).

7. Index of reserves exploration extent. Geological dictionary. "Nedra" Publishing house. 2. p 107. (1987)

8. Parameters. Geological dictionary. "Nedra" Publishing house. 2. p 71. (1987).

9. Parameter. Great Russian Encyclopedia. - M.: "Sovetskaia Entsiklopedia" research publishing house. 25, p 302. (2014). 